\title{
CONSTRUÇÃO DE VÍDEOS EDUCATIVOS SOBRE O USO DE QUESTIONÁRIO ON-LINE NA PESQUISA COM SERES HUMANOS
}

\author{
Raphael Ilidio Arduini \\ Universidade Federal do Triângulo Mineiro \\ raphael.arduini@uftm.edu.br
}

\begin{abstract}
RESUMO
Este estudo descreve o processo de criação de três vídeos educativos sobre o uso de questionários online na pesquisa com seres humanos. Esse estudo foi realizado no contexto de um Comitê de Ética em Pesquisa como forma de desenvolvimento de instruções a pesquisadores que intentam utilizar questionários on-line como instrumento de coleta de dados na pesquisa com seres humanos. Inicialmente foi realizada uma introdução sobre a ética em pesquisa e o questionário como instrumento de pesquisa. O processo de criação do vídeo foi desenvolvido por meio da metodologia de pesquisa-ação, conforme proposto por Michel Thiollent, com um grupo de membros de um comitê de ética em pesquisa. A pesquisa respeitou o ciclo de investigação-ação, cumprindo as etapas de identificação do problema, planejamento, ação, descrição e avaliação. O problema identificado era a ausência de orientações para o uso de questionário on-line. A elaboração do vídeo foi estruturada em etapas, sendo essas a elaboração e aprovação do roteiro, gravação e edição do vídeo e avaliação do vídeo pelos participantes da pesquisa, sendo essas etapas realizadas nas fases de planejamento, ação e avaliação respectivamente. O primeiro vídeo apresenta a ética em pesquisa e o sistema CEP-CONEP; o segundo vídeo aborda o processo de consentimento/assentimento; e o terceiro vídeo, orienta a elaboração de um questionário on-line com o registro do consentimento/assentimento. Os resultados mostraram que os vídeos possuem adequação quanto ao objetivo proposto, forma e conteúdo, e aptidão suficiente para serem utilizados, apontando um caminho para novas produções educativas referentes à ética em pesquisa no futuro.
\end{abstract}

Palavras-chave: ética em pesquisa; questionário on-line; vídeo educativo; pesquisa-ação.

\section{CONSTRUCTION OF EDUCATIONAL VIDEOS ON THE USE OF ONLINE QUESTIONNAIRE IN RESEARCH WITH HUMAN BEINGS}

\begin{abstract}
This study describes the process of creating of three educational videos on the use of online questionnaires in research with human beings. This study was carried out in the context of a Research Ethics Committee as a way of developing instructions for researchers who intend to use online questionnaires as an instrument of data collection in research with human beings. Initially, an introduction was made about research ethics and the questionnaire as a research tool. The video creation process was developed using action research methodology, as proposed by Michel Thiollent, with a group of members of a research ethics committee. The research respected the action-research cycle, fulfilling the stages of problem identification, planning, action, description and evaluation. The problem identified was the lack of guidelines for the use of an online questionnaire. The preparation of the video was structured in stages, which are the preparation and approval of the script, recording and editing of the video and evaluation of the video by the research participants, these
\end{abstract}


stages being carried out in the planning, action and evaluation phases respectively. The first video presents research ethics and the CEP-CONEP system; the second video addresses the consent/assent process; and the third video, guides the preparation of an online questionnaire with the registration of consent/assent. The results showed that the videos have adequacy as to proposed objective, form and content, and sufficient aptitude to be used, pointing a way for new educational productions regarding research ethics in the future.

Keywords: research ethics; online questionnaire; educational video; action research.

\section{CONSTRUCCIÓN DE VIDEOS EDUCATIVOS SOBRE EL USO DE CUESTIONARIO EN LÍNEA EN INVESTIGACIÓN CON SERES HUMANOS}

\section{RESUMEN}

Este estudio describe el proceso de creación de tres videos educativos sobre el uso de cuestionarios en línea en la investigación con seres humanos. Este estudio se realizó en el contexto de un Comité de Ética en Investigación como una forma de desarrollar instrucciones para investigadores que pretendan utilizar cuestionarios en línea como instrumento de recolección de datos en investigaciones con seres humanos. Inicialmente se hizo una introducción sobre la ética de la investigación y el cuestionario como herramienta de investigación. El proceso de creación del video se desarrolló utilizando la metodología de investigaciónacción, propuesta por Michel Thiollent, con un grupo de miembros de un comité de ética en investigación. La investigación respetó el ciclo investigación-acción, cumpliendo las etapas de identificación, planificación, acción, descripción y evaluación del problema. El problema identificado fue la falta de pautas para el uso de un cuestionario en línea. La preparación del video se estructuró en etapas, que son la preparación y aprobación del guión, grabación y edición del video y evaluación del video por parte de los participantes de la investigación, realizándose estas etapas en las fases de planificación, acción y evaluación respectivamente. El primer video presenta la ética de la investigación y el sistema CEP-CONEP; el segundo video aborda el proceso de consentimiento / consentimiento; y el tercer video, guía la elaboración de un cuestionario en línea con el registro de consentimiento / consentimiento. Los resultados mostraron que los videos tienen adecuación en cuanto al objetivo propuesto, forma y contenido, y suficiente aptitud para ser utilizados, señalando un camino para nuevas producciones educativas en materia de ética de la investigación en el futuro.

Palabras clave: ética de la investigación; cuestionario en línea; video educativo; investigación para la Acción.

\section{INTRODUÇÃo}

Em 30 de dezembro de 2019, a Organização Mundial da Saúde foi informada por autoridades chinesas sobre casos de uma pneumonia de etiologia desconhecida (WHO, 2020). A causa, a época incógnita, seria posteriormente identificada como um vírus estirpe da espécie Coronavírus relacionado com a síndrome respiratória aguda grave (SARS-Cov) (GORBALENYA et al., 2020). O primeiro registro oficial da doença ocorreu na cidade Wuhan, na província de Hubei, localizada na região central da República Popular da China (WHO, 2020). Com um número efetivo de reprodução alto, a Covid-19 foi declarada como pandemia em 11 de março de 2020 pela Organização Mundial de Saúde (CAICEDO-OCHOA, 2020). A pandemia provocada pelo SAR- 
CoV-2, vírus causador de síndrome respiratória aguda, apresentou impacto significativo nos meios de vida da população mundial (OPAS, 2020).

Diante do alto grau de contaminação apresentado pelo vírus da Covid-19, o distanciamento social foi a resposta de enfretamento adotada com maior frequência no mundo e no Brasil (BEZERRA et al., 2020). “O distanciamento social envolve medidas que têm como objetivo reduzir as interações em uma comunidade, que pode incluir pessoas infectadas, ainda não identificadas e, portanto, não isoladas.” (AQUINO et al., 2020, p. 2425). Como consequência do distanciamento social, medidas adaptativas tiveram que ser colocadas em prática por parte das autoridades públicas para obtenção do objetivo de achatamento da curva de contaminação pelo vírus (SCHWARTZ, 2020).

Comumente presente entre as ações de distanciamento social, o fechamento de escolas e universidades impactou diretamente na forma como o planejamento, a gestão, e a docência, se desenvolveram durante o isolamento social (SOUSA et al., 2020). Sem a possibilidade de execução de atividades presencialmente, ferramentas virtuais, disponíveis na internet, tornaram-se a principal solução para manter as atividades educacionais e a comunicação ativas durante o período de distanciamento (SAMPAIO, 2020; PASINI; CARVALHO; ALMEIDA, 2020).

A rede mundial de computadores, ou internet, desde seu lançamento comercial na década de noventa, tornou-se, no decorrer dos anos, essencial para o funcionamento da sociedade moderna (OLIVEIRA, 2014). Não apenas como entretenimento, mas se integrando nas tarefas diárias, a internet vem substituindo e complementando a correspondência postal, a comunicação telefônica, sistemas de comunicação financeira, dentre outros. A dependência das tecnologias tem aumentando cada dia mais, e o convívio com a internet está presente em todas as esferas da vida. (CAMPOS; PAULA, 2020).

As funcionalidades proporcionadas pela internet, hoje essenciais, tiveram início com o surgimento da Web 2.0, que se caracterizou, principalmente, pela transição do usuário exclusivamente consumidor de conteúdo, para o usuário produtor de conteúdo. As primeiras experiências do modelo aconteceram com o surgimento dos serviços de blogs, que ofertavam espaços para publicação de textos on-line, contudo, com o rápido desenvolvimento das tecnologias da informação na década de dois mil, outros serviços despontaram e tornaram-se disponíveis recursos que convergiam fotos, vídeos, armazenamento de dados e transmissões (OLIVEIRA, 2014).

A inovação tecnológica que sustentou essa transição foi o “Cloud Computating”, em tradução livre, computação em nuvem, tecnologia que possibilitou o funcionamento de sistemas inteiros dentro da rede, proporcionando a não-localidade da informação, tornando-a acessível em qualquer ponto da rede. Com a computação em nuvem, infraestruturas, plataformas e softwares começaram 
a serem ofertados como serviços na internet e o acesso a aplicações que operavam inteiramente online. Essa característica é o elemento essencial do desenvolvimento do Software as a Service (SaaS) que é definido como "[...] um ambiente operacional completo com aplicativos, gerenciamento e interface do usuário [...]" (VIKRAM, 2013, p. 190) e, possibilitou o uso de aplicações digitais sem a necessidade de instalação dessas nos dispositivos dos usuários. No novo modelo, as aplicações são disponibilizadas como serviços, e não como produtos.

O desenvolvimento das Tecnologias da Informação e Comunicação (TIC) viabilizou o surgimento de diversos serviços on-line, dentre os quais, destacam os sítios wiki (sítios voltados registro, aglutinação e pesquisa de informações dispostas de forma colaborativa), as redes sociais e sítios que ofertam aplicações aos usuários - como ferramentas de produção de texto, navegação, mapeamento, armazenamento de dados, veiculação de conteúdos audiovisuais, dentre outros. (VIKRAM, 2013). Nesse contexto, cabe o destaque aos serviços de criação de questionários de aplicação e divulgação integralmente on-line, customizáveis conforme as necessidades dos usuários.

Quanto a sua aplicação no universo da pesquisa científica, Freitas et al. pontuam que a "Internet oportuniza uma forma de coleta e de disseminação das informações nunca antes possível de ser realizada. Com ela, o pesquisador não está mais limitado pelas restrições de tempo, custo e distância, possuindo um acesso mundial praticamente instantâneo, com despesas mínimas”. (FREITAS et al. 2004, p. 1).

O processo de pesquisa com o apoio das novas tecnologias não se resume a mecanização dos processos e disponibilização on-line, mas significa a dinamização de todo o rito da pesquisa, passando pela seleção interativa da amostra, o acompanhamento em tempo real da coleta de dados, a disponibilização instantânea e tabulada dos dados coletados e a capacidade de atingir indivíduos em qualquer lugar que disponha de conexão à rede (FREITAS et al., 2004).

O uso de ambientes virtuais, tornou economicamente viáveis, pesquisas que por outros meios não seriam, colaborando para o aumento da velocidade da informação e da produção científica. Esse novo modelo, em que a coleta de dados ocorre com emprego de questionário e divulgação virtual, alçou-se à primeira escolha, ao se tratar da realização de pesquisas que envolvem diversos países, por dispor de rapidez, economicidade e satisfatório aproveitamento de respostas. (FALEIROS, 2016).

Torrini (2016, p. 55) define os questionários on-line como “[...] um tipo específico de questionário enviado/recebido e preenchido pelos respondentes por meio da internet". Para o autor, não são todos os instrumentos eletrônicos de pesquisa considerados questionários on-line, certo que esses necessitam que uma de suas etapas de uso aconteça na internet, e aqueles não, bastando serem 
realizados com algum dispositivo eletrônico. Sendo assim, questionários aplicados por meios eletrônicos, como telefone, não poderiam ser considerados questionários on-line.

A utilização de questionário on-line apresenta vantagens e limitações em comparação a outros meios de aplicação. Vasconcellos e Guedes (2007) mostram que a principal limitação em sua utilização é o viés da amostra, visto que meios virtuais, apesar do crescimento constante do número de usuários da internet, tendem a ter menos adesão em faixas etárias mais avançadas da população. Contudo, dentre as vantagens, os autores apontam que há, principalmente, ganhos de eficiência econômica e temporal, considerando que o envio, o recebimento e a confirmação da resposta ocorrem instantaneamente; a tabulação dos dados ocorre de forma automatizada; e os custos são praticamente inexistentes nos casos em que o pesquisador já possui acesso à internet (VASCONCELLOS; GUEDES, 2007).

Evans e Mathur (2005) alertam ainda para limitações quanto a (1) escolha do envio, visto que por e-mail pesquisas surveys (fundamentadas na aplicação de questionário) podem passar por lixo eletrônico; (2) atributos enviesados da amostra, quando a forma de divulgação atinge apenas um determinado nicho dentro da rede; (3) seleção e representatividade da amostra; (4) falta de habilidade dos respondentes; (5) variação da tecnologia, que ocorre quando a proposta do survey on-line não se adequa as tecnologias disponíveis aos respondentes; e (6) complexidade na instrução de respostas (EVANS; MATHUR, 2005).

Para além da esfera prática, a adesão cada vez maior a meios virtuais de pesquisa, suscita considerações de outras dimensões, dentre as quais, destaca-se a esfera ética. A ética na pesquisa científica com seres humanos teve seu marco inicial durante os julgamentos dos crimes bioéticos cometidos por cientistas do regime nazista durante a segunda guerra mundial. Para auxiliar os julgamentos, foi produzido e aprovado o Código de Nuremberg de 1947, que entrou para a história como o primeiro ato normativo a estabelecer parâmetros para realizações de intervenções biomédicas em seres humanos com finalidade de pesquisa cientifica. Apesar dos esforços propostos pelo referido Código, abusos bióticos continuaram a assolar a pesquisa com seres humanos nas décadas seguintes, o que impulsionou a Associação Médica Mundial a criar a Declaração de Helsinque. (TEIXEIRA et al., 2012).

A Declaração de Helsinque (1964) previu pela primeira vez, de forma explicita, que os interesses do paciente deveriam sempre prevalecer sobre os interesses da sociedade e da ciência. Em sua primeira revisão, em 1975, a declaração passou a observar a importância e necessidade de os protocolos de pesquisa serem analisados e acompanhados por comitês independentes dos pesquisadores e dos patrocinadores dos estudos (FREITAS, 1998). 
No Brasil, o Conselho Federal de Medicina estabeleceu, em 1984, no Código Brasileiro de Deontologia Médica, a vedação a médicos em exercício da profissão de realizar estudos clínicos sem aprovação e acompanhamento por uma Comissão de Ética. Essa medida culminaria em sua revisão em 1988 com a exigência da submissão dos protocolos de pesquisa, a aprovação e acompanhamento de comissões independentes dos pesquisadores. (FREITAS, 1998).

No mesmo ano, o Conselho Nacional de Saúde (CNS) exararia o primeiro marco regulatório das pesquisas em saúde, a Resolução CNS 01/88, que determinava que toda instituição de saúde credenciada pelo Conselho deveria então manter um Comitê de Ética responsável pela avaliação e acompanhamento das pesquisas clínicas. Contudo, em 1995, ao verificar a baixa adesão das instituições na formação e funcionamento de seus Comitês de Ética em Pesquisa, o Conselho Nacional de Saúde propôs a revisão da Resolução CNS 01/88 criando assim a Resolução CNS 196/96 (FREITAS, 1998).

A Resolução 196/96 além de reunir as diretrizes para apreciação ética dos protocolos de pesquisa, também instituiu o sistema responsável pelo seu acompanhamento. Esse sistema compunha-se pela Comissão Nacional de Ética em Pesquisa (CONEP) e pelos Comitês de Ética em Pesquisa das instituições proponentes das pesquisas (BRASIL, 1996). Esse sistema foi criado sobre a prerrogativa de utilização de "[...] mecanismos, ferramentas e instrumentos próprios de interrelação, num trabalho colaborativo que visa, especialmente, à proteção dos participantes de pesquisas no Brasil, de forma coordenada e descentralizada por meio de um processo de acreditação.” (BRASIL, 2012).

Em 2011, quinze anos após sua aprovação, a Resolução 196/96 passou por um processo de revisão que se iniciou com uma consulta pública, da qual resultou sugestões de alteração da resolução. As sugestões foram discutidas e compiladas em um documento durante o Encontro Nacional dos Comitês de Ética em Pesquisa (ENCEP). Esse documento foi enviado a CONEP, que em dezembro de 2012, em sua $240^{\mathrm{a}}$ reunião Ordinária aprovou o novo documento, que passou a vigorar como Resolução CNS 466/12, revogando assim a resolução CNS 196/96 (NOVOA, 2014).

A resolução 466/12 diferenciou-se da resolução 196/96, principalmente, por ser mais longa e filosófica, proporcionando um contexto mais elaborado em referências aos princípios da bioética. A resolução 466/12 pauta-se pelos princípios da autonomia, não maleficência, beneficência, justiça e equidade, dentre outros, visando "[...] assegurar os direitos e deveres que dizem respeito aos participantes da pesquisa, à comunidade cientifica e ao Estado.” (BRASIL, 2012, p. 02).

Ambas as resoluções CNS 196 e 466 preveem que o respeito à dignidade humana exige que todas as pesquisas com seres humanos se processem apenas, e após, o processo de consentimento livre e esclarecido dos indivíduos. Esse procedimento é um instrumento de proteção a autonomia da 
vontade do participante das pesquisas, ao mesmo tempo que estabelece as obrigações que os pesquisadores e eventuais patrocinadores dos estudos possuem com os participantes.

O processo de consentimento livre e esclarecido perfaz-se somente se cumpridas as etapas que assegurem que o participante possa manifestar seu consentimento de forma autônoma, consciente, livre e esclarecida. A resolução CNS 466/12 divide esse processo em duas etapas, a inicial, de esclarecimento e a final, de consentimento. (BRASIL, 2012).

A etapa inicial consiste, primeiramente, na escolha adequada da ocasião para a realização do esclarecimento, considerando assim as peculiaridades do convidado a participar da pesquisa e sua privacidade; durante o esclarecimento, as informações prestadas devem ser claras e acessíveis, observando suas adequação a cultura, faixa etária, condição socioeconômica e autonomia dos convidados a participar da pesquisa; por fim, o esclarecimento deve ser acompanhado de tempo adequado para o convidado refletir, e, se necessário, consultar terceiros que possam o ajudar no processo decisório. (BRASIL, 2012).

Superada a etapa inicial, a resolução prevê que o pesquisador deve apresentar um instrumento que registre o processo, e a esse documento dá o nome de Termo de Consentimento livre e Esclarecido (TCLE). O TCLE, ressalvadas as exceções, sempre deverá ser concedido ao participante, ou a seu representante legal, para que seja lido e compreendido, antes que ocorra a concessão do consentimento livre. O consentimento é uma manifestação de vontade que deve ser fundada em informações verídicas, claras e em concordância com o que determina a bioética e a ética em pesquisa como um todo. (BRASIL, 2012).

O Termo de Consentimento Livre e Esclarecido (TCLE) é um documento impreterível, ressalvadas exceções, no processo de consentimento, esse documento deve abrigar todos os detalhes a respeito de direitos, garantias e deveres estabelecidos na relação participante-pesquisa. O TCLE deve conter as justificativas, objetivos e os procedimentos que serão utilizados na pesquisa, assim como a explicitação dos possíveis desconfortos e riscos decorrentes da pesquisa. (BRASIL, 2012).

As garantias que o participante possui também devem ser explicitadas no documento, quais sejam: plena liberdade em recusar-se a participar ou retirar seu consentimento em qualquer etapa da pesquisa; manutenção do sigilo e privacidade do participante; recebimento de segunda via do TCLE; ressarcimento e cobertura de despesas; indenização diante de eventuais danos decorrentes da participação na pesquisa. (BRASIL, 2012).

Algumas pesquisas, por possuírem características excepcionais, possuem, na Resolução CNS 466/12, salvaguardas que possibilitam o pedido de dispensa da obtenção do Termo de Consentimento Livre e Esclarecido. A Resolução em seu item "IV.8" prevê que nos casos em que a obtenção do TCLE seja inviável; represente riscos substanciais à privacidade e confidencialidade 
dos dados do participante; ou riscos aos vínculos de confiança entre pesquisador e pesquisado, o pesquisador poderá solicitar justificadamente um pedido de dispensa ao sistema CEP-CONEP, esse analisará o pedido e decidirá seu mérito (BRASIL, 2012).

Para pesquisas que possuem em seu universo de participantes menores de idade ou indivíduos legalmente incapazes, a Resolução 466/12 prevê a necessidade da obtenção do assentimento. O assentimento é a anuência de indivíduos que não possuem capacidade legal plena e sua participação adstringe ao consentimento de seus responsáveis legais que deve ser obtido em conjunto ao seu assentimento. A obtenção do assentimento deve ser realizada seguindo os mesmos princípios e diretrizes do Consentimento. (BRASIL, 2012).

Em 2013, em esforço para mitigar as inadequações da Resolução 466/12 para metodologias de pesquisas além do âmbito biomédico, a CONEP organizou o Grupo de Trabalho em Ciências Humanas e Sociais (GT-CHS), com o objetivo de elaborar uma minuta de resolução que teria por objeto tratar das especificidades das pesquisas em Ciências Humanas e Sociais (GUERRIERO, 2016).

O processo foi iniciado na própria Resolução CNS 466/12 que em seu item "XIII.3” prevê que "[...] as especificidades éticas das pesquisas nas ciências sociais e humanas e de outras que se utilizam de metodologias próprias dessas áreas serão contempladas em resolução complementar, dadas suas particularidades." (BRASIL, 2012, p. 12).

O trabalho do GT CHS da CONEP decorreu-se de 2013 a 2016, e resultou na publicação, em maio de 2016, da Resolução CNS 510. Dentre as diretrizes tratadas pela referida resolução, destacase a ampliação da definição do processo de consentimento. Atendendo a especificidades das pesquisas científicas em Ciências Humanas e Sociais, a nova resolução definiu o consentimento como sendo o "[...] processo pautado na construção de relação de confiança entre pesquisador e participante da pesquisa, em conformidade com sua cultura e continuamente aberto ao diálogo e ao questionamento, não sendo o registro de sua obtenção necessariamente escrito.” (BRASIL, 2016, p. 4). Outro elemento-chave na nova resolução era que o consentimento não necessariamente deveria ser salvaguardado no início da pesquisa, “[...] podendo ser obtido ou registrado em qualquer das fases de execução da pesquisa." (BRASIL, 2016, p. 7).

Essa expansão conceitual do consentimento aplicada às pesquisas em Ciências Humanas e Sociais também ampliou as possibilidades para o registro do consentimento, pois prevê que o

[...] registro do consentimento ou do assentimento: documento em qualquer meio, formato ou mídia, como papel, áudio, filmagem, mídia eletrônica e digital, que registra a concessão de consentimento ou de assentimento livre e esclarecido, sendo a forma de registro escolhida a partir das características individuais, sociais, linguísticas, econômicas e 
culturais do participante da pesquisa e em razão das abordagens metodológicas aplicadas (BRASIL, 2016, p. 4).

Com isso, a ética em pesquisa e as Inovações Tecnológicas no âmbito das Tecnologias da Informação e Comunicação (TIC) ganharam maior proximidade, visto que os registros e processo de consentimento passam a contemplar novas formas de consecução, abrindo espaço para ferramentas digitais serem aplicadas. O progresso normativo da ética em pesquisa, no mundo e no Brasil, percorreu uma extensa linha temporal até chegar na resolução CNS 510/16, de forma que a realização de pesquisas em meios virtuais fossem possíveis a tempo de minimizar limitações extraordinárias, como as causadas por uma pandemia.

Esta pesquisa foi realizada na Universidade Federal do Triângulo Mineiro (UFTM), especificadamente em seu Comitê de Ética em Pesquisa. O Comitê é um colegiado interdisciplinar e independente, de relevância pública, possui caráter consultivo, deliberativo e educativo; tem como missão defender os interesses dos participantes da pesquisa quanto a sua integridade e dignidade e para contribuir no desenvolvimento da pesquisa dentro de padrões éticos. (BRASIL, 2012).

Quadro 1 - Critérios de inclusão e exclusão.

\begin{tabular}{|c|c|c|}
\hline Participantes & Critérios de Inclusão & Critérios de Exclusão \\
\hline $\begin{array}{l}\text { Membros do CEP- } \\
\text { UFTM }\end{array}$ & $\begin{array}{l}\text { 1. Ser membro ativo do CEP-UFTM; } \\
\text { 2. } 6 \text { meses de experiência na função; } \\
\text { 3. Ter presença de } 50 \% \text { nos últimos } \\
\text { seis meses; } \\
\text { 4. Ter acesso a internet. }\end{array}$ & $\begin{array}{l}\text { 1. Não ter realizado relatoria em protocolo de } \\
\text { pesquisa com seres humanos. }\end{array}$ \\
\hline
\end{tabular}
Fonte: Do autor, 2021.

Referente a considerações éticas, essa pesquisa foi submetida a apreciação ética sobre o Certificado de Apresentação para Apreciação Ética (CAAE) 40456820.9.0000.5154, e foi aprovada sob o parecer de número 4.432.817. Ao realizar as considerações ética do estudo, entendeu-se que o único risco presente nessa pesquisa era o risco de perda de confidencialidade, esse poderia se concretizar em dois momentos, durante a etapa do seminário e durante a etapa de avaliação do vídeo.

\section{METODOLOGIA}

Esta pesquisa teve como objetivo geral a construção de vídeos educativos sobre como utilizar questionários on-line na pesquisa com seres humanos e como objetivos específicos a elaboração de um roteiro para a construção do vídeo educativo; a análise do roteiro em seminário junto aos membros do Comitê de Ética em Pesquisa da Universidade Federal do Triângulo Mineiro; a 
elaboração e descrição do processo de desenvolvimento do vídeo educativo; e finalmente, a avaliação do vídeo finalizado junto aos membros do Comitê de Ética em Pesquisa da UFTM

Esse estudo foi desenvolvido mediante a aplicação da metodologia de pesquisa-ação, com a realização de um processo de investigação-ação para a elaboração de vídeos educativos sobre a utilização de questionários on-line em conformidade com a normatização da ética em pesquisa no Brasil.

A metodologia de pesquisa-ação, proposta por Michel Thiollent, enquanto linha de pesquisa orientada em função da resolução de problemas ou de objetivos de transformação, é definida como

[...] um tipo de pesquisa social com base empírica que é concebida e realizada em estreita associação com uma ação ou com a resolução de um problema coletivo e no qual os pesquisadores e os participantes representativos da situação ou do problema estão envolvidos de modo cooperativo ou participativo. (THIOLLENT, 1986, p.14).

Para Tripp (2005), a pesquisa-ação caracteriza-se como um tipo de investigação-ação, que possui como elemento básico um ciclo no qual se aprimora a prática através da ação e investigação. "Planeja-se, implementa-se, descreve-se e avalia-se uma mudança para a melhora de sua prática, aprendendo mais, no correr do processo, tanto a respeito da prática quanto da própria investigação.” (TRIPP, 2005, p. 446). O processo de investigação-ação que foi aplicado pode ser pormenorizado da seguinte forma:

a) Identificação do problema: carência de orientações para realização de pesquisa com questionários on-line em acordo com a ética em pesquisa com seres humanos.

b) Planejamento: composto pela pesquisa bibliográfica sobre as normatizações da ética em pesquisa, e metodologia de elaboração de vídeos educativos; elaboração de seminário para apresentação e aprovação da proposta de roteiro para construção do vídeo educativo aos membros do Comitê de Ética em Pesquisa da UFTM; e acolhimento de edições propostas e aprovadas por esses membros;

c) Ação: realizar a construção do vídeo educativo, fundamentada no roteiro discutido e editado com os membros do Comitê de Ética em Pesquisa;

d) Descrição: relato de todo o processo de planejamento e construção do vídeo com apresentação do embasamento normativo para as orientações contidas no vídeo.

e) Avaliação: envio do vídeo construído para avaliação dos membros do Comitê de Ética em Pesquisa seguindo critério pré-estabelecidos.

Na pesquisa-ação, uma capacidade de aprendizagem é associada ao processo de investigação. Nesse contexto, cabe aos atores a geração e a utilização das informações, consequentemente, 
ordenar a ação, formar decisões, etc. Esse processo integra tanto a atividade planejada, quanto a atividade cotidiana e não pode deixar de ser diretamente observada durante o processo de pesquisaação. (THIOLLENT, 1986).

A investigação envolve produção e circulação da informação, elucidação e tomada de decisões e outros aspectos supondo uma capacidade de aprendizagem dos participantes. Esses já possuíam essa capacidade adquirida na atividade normal, e, no processo da pesquisa-ação, essa capacidade foi aproveitada e enriquecida em função das exigências da ação em torno da qual se desenrolou a investigação.

A natureza dinâmica do processo de investigação-ação fez-se presente, visto que o ciclo completo não ocorreu de forma linear. O ciclo de investigação-ação dentro da pesquisa agrega em cada etapa, pequenos ciclos internos. (TRIPP, 2005). Nesta pesquisa, como exemplo, foi possível identificar ações e avaliações na fase de planejamento - sendo que a construção do roteiro passou por apresentação, avaliação e adequação.

A elaboração narrativa de um vídeo educativo, assim como em filmes, é diretamente influenciada por pressupostos conscientes e inconscientes a respeito do público-alvo do material produzido. Essa dinâmica, além de considerar as características do conteúdo tratado no vídeo, também se atenta às pressuposições a respeito dos espectadores em potencial. Esse relacionamento entre o que pressupõe que será recepcionado, e o conteúdo produzido, é desenvolvido considerandose o modo de endereçamento. (BASTOS; REZENDE FILHO; PASTOR JUNIOR, 2015).

Contudo, ocasionadas pelo distanciamento entre o produtor audiovisual e o espectador real do conteúdo, discordâncias entre a leitura realizada por parte do espectador e as preconcepções consideradas no endereçamento podem surgir. Essas discordâncias interferem na produção de sentido durante a recepção do vídeo, ocasionando resistências às perspectivas e aos conteúdos tratados. (PASTOR JUNIOR; REZENDE; BASTOS, 2012).

A recepção da mensagem no intuito de produção de sentido deve ser considerada um fenômeno multidimensional, não linear e condicionada, tanto por elementos previamente determinados, quanto por elementos não determinados. Esse processo de recepção decorre de uma decodificação em que se estabelece uma relação complexa, permeada de indeterminações e variáveis, entre o conteúdo e as bases em que esse é assimilado. (ESCOSTEGUY, 2007).

Essa complexidade origina-se na ausência de transparência da produção e recepção da mensagem, visto seu caráter multirreferencial de conteúdo e a diversidade de sistemas referenciais considerados em sua recepção (social, cultural, profissional, ideológico, escolaridade etc.) pode resultar em diversidade de leituras e posicionamentos frente à obra audiovisual. (BASTOS; REZENDE FILHO; PASTOR JUNIOR, 2015). 
A proposta do roteiro, orientou-se sobre a premissa de que o receptor da mensagem é um agente a procura de informações, para elaboração adequada de um questionário on-line, em uma pesquisa com seres humanos, assim, preconcebeu-se que a mensagem a ser decodificada deveria gozar de conteúdo prático aplicado a realidade do receptor, visando a suscitar diminuto conflito entre o código explorado e a produção de sentido do receptor da mensagem. Com isso, a escolha do meio de transmissão privilegiou o formato audiovisual, considerando o seu caráter sedutor, que objetiva oferecer ao público algo necessário, proporcionando assim satisfação. (SILBIGER, 2005).

\section{DESENVOLVIMENTO}

No processo de idealização e elaboração do roteiro para o vídeo, buscou-se atenção aos referidos princípios de forma a ampliar a eficácia do vídeo produzido. Fatores como tempo, especificidade do público, dos objetivos propostos e relevância, foram atendidos e observados para produzir maior impacto na população alvo da educação proposta no vídeo.

O roteiro foi estruturado a partir de uma adaptação do que propõe Comparato (2009), que define a construção do roteiro em seis etapas: ideia, conflito, personagens, ação dramática, tempo dramático e unidade dramática. A primeira etapa, a ideia, parte sempre de um fato que o escritor reconhece relevância suficiente em relatar, o 'o que' da história, que no caso em mão, se trata do uso do questionário on-line na pesquisa com seres humanos. A segunda etapa decorre do conflito, que em essência, é a matriz do que se quer contar, essa matriz, segundo Comparato, deve ser estabelecida em um story line, que consiste na “[...] condensação do nosso conflito básico cristalizado em palavras.” (COMPARATO, 2009, p. 37).

O story line proposto no roteiro do vídeo foi “A pesquisa com seres humanos possui regras a serem observadas, essas regras são fiscalizadas por um sistema, e a forma de aplicar essas regras na pesquisa com uso de questionários on-line seguem um rito específico.”. O roteiro segue com o estabelecimento das personagens, contudo no vídeo educativo, o personagem é o próprio interlocutor e sua história é descrita em forma da ação transmitida durante o desenvolvimento da narrativa do vídeo, nesse momento é estabelecido o 'quem' e o 'quando', para o que é, considerouse o pesquisador e o quando, o momento de se propor o uso do questionário on-line na pesquisa com seres humanos.

A quarta etapa evidencia a ação dramática, o desenrolar dos fatos propostos no roteiro, o ‘como'; após definido o que, o quem e o quando, emerge-se então o como esses fatos se desenrolam, ao se adaptar à realidade do vídeo educativo, esse ‘como' são os meios que devem ser percorridos no realizar da personagem. 
A quinta etapa é o tempo dramático, Comparato afirma que "[...] o tempo dramático é o quanto, quanto tempo terá cada cena" (COMPARATO, 2009, p. 40), no caso do material proposto esse tempo é divido em três, a introdução (à ética em pesquisa e ao sistema CEP-CONEP), a preparação do contexto (apresentação do processo de consentimento/assentimento), e o desfecho (a aplicação do questionário on-line com consentimento/assentimento).

Por último, a sexta etapa, unidade dramática, que é o guia para elaboração do vídeo, o pormenor de tudo que deve ser abordado, gravado e como ser feito (COMPARATO, 2009).

Após a construção da proposta de roteiro passou-se a parte de aprovação desse, esse procedimento foi realizado a partir de um seminário com os participantes da pesquisa. O seminário é um procedimento previsto por Thiollent (1986), em que se reuni os pesquisadores com os participantes do estudo, com o intuito de examinar, discutir e tomar decisões acerca do processo de investigação. O seminário concentra todas as informações coletadas e oportuniza ocasião para a discussão de suas interpretações. "Com as informações reunidas, e dentro da perspectiva teórica adotada, o seminário elabora diretrizes de pesquisa (hipóteses) e diretrizes de ação submetidas à aprovação dos interessados, que serão testadas na prática dos atores considerado." (THIOLLENT, 1986, p. 58).

Diante disso, cabe destacar o caráter participativo da pesquisa-ação, pois um dos pressupostos basilares desse processo é que todos os agentes atingidos pela mudança também participem dela. No viés prático assume-se que o mais adequado seja que o processo ocorra de forma otimizada quando por cooperação e colaboração sendo que os efeitos produzidos por um indivíduo dentro de uma organização jamais se limitam exclusivamente a ele (TRIPP, 2005).

Pela característica participativa, optou-se por uma amostragem intencional, que se trata de um pequeno número de pessoas selecionadas intencionalmente, de forma não probabilística, em função da relevância que elas apresentam em relação a um determinado assunto ou sua representatividade perante o grupo que pertence. (THIOLLENT, 1986; GIL, 2008).

Para este estudo entendeu-se que dentre os quatro modelos de participação apresentados por Tripp (Obrigação, Cooptação, Cooperação e Colaboração), o modelo adequado é o de cooperação, que ocorre "[...] quando um pesquisador consegue que alguém concorde em participar de seu projeto, a pessoa que coopera trabalha como parceiro sob muitos aspectos - uma vez que é regularmente consultado." (TRIPP, 2005, p. 454).

Conseguinte, foi realizado o convite formal aos membros do CEP-UFTM, para o qual foi apresentado o Termo de Consentimento Livre e Esclarecido e respeitadas todas as etapas do processo de consentimento. Aqueles que consentiram participar da pesquisa foram convidados para, 
em data comum a todos, participarem do seminário da proposta de roteiro com o objetivo de discutir, propor alterações e aprovar o roteiro.

O seminário aconteceu no dia dez de dezembro de 2020 e foi atendido por seis participantes todos membros do Comitê de Ética, todos atenderam aos critérios de inclusão e não foram atingidos pelo critério de exclusão. Os participantes constituíam uma amostra variada, com profissionais de diversas áreas do conhecimento, representando, com o pesquisador que também participou ativamente do processo, número superior a 50\% dos indivíduos elegíveis no universo estudado.

O processo de apresentação foi realizado por intermédio do Google Meet, serviço de videoconferência on-line ofertado pela empresa Google, com a qual os participantes já possuíam familiaridade, por utilizarem em suas atividades acadêmicas.

A apresentação do roteiro foi amparada por vídeo piloto para ilustrar a estrutura do roteiro e facilitar a compreensão imagética da proposta. $\mathrm{O}$ vídeo piloto foi exibido durante a videoconferência do seminário.

Ao término da apresentação, foi realizada uma roda de conversa, em orientação alfabética, onde todos os membros participantes deram seu parecer oral sobre a proposta. Terminadas as explanações dos participantes, todas as propostas recepcionadas foram votadas pelos participantes, e, assim, foram determinadas como linhas guias para serem colocadas em prática. Todo o procedimento foi conduzido pelo pesquisador discente desse estudo com apoio da coordenação do comitê.

Uma vez apresentado o roteiro, todas as propostas acatadas dos participantes foram transcritas, sem identificação do autor, para análise de seus conteúdos. Todas as recomendações e observações foram salvas em vídeo e depois de transcritas, apagadas.

Finalmente, após a transcrição de todas as propostas, aquelas aprovadas pelos participantes foram incorporadas no roteiro, e, assim, o vídeo foi produzido. Ressalta-se que todas foram aprovadas, mas algumas não foram incorporadas no roteiro por questões técnicas.

A análise ocorreu com o emprego de análise de conteúdo,

[...] a análise de conteúdo é um conjunto de técnicas de análise das comunicações. Não se trata de um instrumento; mas de um leque de apetrechos; ou, com maior rigor, será um único instrumento, mas marcado por uma grande disparidade de formas e adaptável a um campo de aplicação muito vasto: as comunicações (BARDIN, 1977, p.31).

Referente a esfera da análise de conteúdo, buscou-se o emprego da análise estrutural sem enfoque no vocabulário, léxico ou repertório semântico ou temático da mensagem, mas nos princípios de organização, implícitos ou encobertos da mensagem, evidenciados por suas relações, 
esquemas direcionadores, encadeamentos, associações, exclusões, equivalências, organizadores, elementos de significação e figuras de retórica. Sendo assim, o objeto da análise não se ateve apenas a denotação da mensagem, mas, principalmente, a conotação que essa abrigava, expressada pelas relações estruturantes dos signos ou significações do discurso.

Pela análise do conteúdo do seminário constatou-se que foram feitos trinta e sete apontamentos realizados, que foram aglutinadas em quatro categorias: textuais, conteúdo, elementos visuais e apresentação, conforme apresentado no Quadro 2.

Quadro 2 - Aglutinação das propostas por categorias observadas.

\begin{tabular}{|c|c|}
\hline Categorias: & Propostas: \\
\hline Conteúdo & $\begin{array}{l}\text { Utilizar a expressão "Eu consinto", em vez de "Consinto" apenas; } \\
\text { Abordar mais sobre a resolução } 510 / 16 \text {; } \\
\text { Dividir o vídeo em dois; } \\
\text { Não usar as expressões } 1^{\circ}, 2^{\circ} \text { e } 3^{\circ} \text { parágrafo durante a orientação do TCLE; } \\
\text { Melhorar a explicação no vídeo tutorial de como vincular a resposta ao } \\
\text { direcionamento da sessão; } \\
\text { Repensar a necessidade de explicar sobre onde o formulário será salvo; } \\
\text { Atentar a explicação de nomear o formulário; } \\
\text { Substituir a definição "tamanho" ao explicar o TCLE, por "número de } \\
\text { questões" ou "tempo estimado para resposta"; } \\
\text { Não aprofundar demasiadamente nas explicações sobre o Google Forms; } \\
\text { Ressaltar que podem ser utilizados outros serviços de formulários on-line; } \\
\text { Explicar a opção imprimir como processo de salvamento do formulário em } \\
\text { PDF, para envio na durante a submissão da Plataforma Brasil; } \\
\text { Inserir a informação sobre a possibilidade do uso de imagem no momento } \\
\text { do esclarecimento do Termo de Consentimento Livre e Esclarecido; } \\
\text { Suprimir o termo Nazista do roteiro; }\end{array}$ \\
\hline Elementos Sonoros & $\begin{array}{l}\text { Sincronizar as falas com as ações do vídeo tutorial; } \\
\text { A música de fundo tira a atenção que já está muito requisitada; } \\
\text { Proporção dos volumes da trilha sonora e do áudio da narração; }\end{array}$ \\
\hline Elementos Visuais & $\begin{array}{l}\text { Criar um e-mail anônimo específico para a captura de tela da orientação; } \\
\text { Aumentar a diversidade dos modelos que aparecem no vídeo; } \\
\text { Fazer avatar do apresentador; } \\
\text { Não utilizar imagens dos Nazistas; } \\
\text { Inserir tradução em Libras; } \\
\text { Criar transições entre os assuntos; } \\
\text { Usar fontes sem serifa; } \\
\text { Substituir a imagem de fundo do apresentador durante o momento de } \\
\text { "Atenção"; } \\
\text { Utilizar um TCLE fictício preenchido para fazer a orientação; } \\
\text { Utilizar recursos mais evidentes para apontar os botões que devem ser } \\
\text { clicados; } \\
\text { Colocar o texto dos trechos do TCLE quando estiver explicando; } \\
\text { Ter atenção aos dados dispostos no computador que for usado para fazer a } \\
\text { captura de imagem durante o processo de execução dos procedimentos a } \\
\text { serem realizados; } \\
\text { Evitar textos na cor branco em fundo claro, escolher um fundo que dê } \\
\text { contraste; }\end{array}$ \\
\hline Apresentação & $\begin{array}{l}\text { Interagir com os recursos visuais utilizados no vídeo; } \\
\text { Atenção a entonação da voz; } \\
\text { Aumentar o uso de recursos de postura; } \\
\text { Aplicar recursos de discursos; } \\
\text { Melhorar o carisma durante a apresentação do vídeo; }\end{array}$ \\
\hline
\end{tabular}


Atenção à cadência durante a explicação do Termo de Consentimento Livre e Esclarecido;

Aumentar o tempo entre períodos;

A velocidade da fala deveria ser planejada, pois o volume de informações proposto e tempo do vídeo piloto não estavam compatíveis;

Fonte: Do autor, 2021.

Após finalizar o roteiro do vídeo, seguindo as edições propostas pelos participantes, iniciouse a elaboração do vídeo. A produção do vídeo começou pela escolha do cenário, em que seriam realizadas as filmagens do apresentador. O cenário preferencialmente deveria contar com boa acústica, para evitar reverberações sonoras indesejadas; relativa ausência de ruídos externos, para não comprometer a qualidade sonora da gravação; assim como iluminação satisfatória, para evitar problemas de luz e nitidez das imagens captadas.

Durante as gravações, foi utilizado um tecido verde para a realização da composição de imagem com emprego da técnica de Chroma Keying. Essa técnica acontece quando uma imagem gravada se utiliza de um fundo unicolor, preferencialmente uma cor com boa saturação, normalmente verde florescente ou azul celeste, e, durante o processo de edição, tem sua parte unicolor retirada para dar lugar a outra imagem subposta a imagem gravada, no fundo. Essa composição pode ser realizada por meio de equipamento (hardware) ou aplicações (software), sendo a última, a mais moderna e utilizada nos dias atuais. (VAN DEN BERGH; LALIOTI, 1999).

As aplicações utilizadas na edição foram o Filmora, editor de vídeo da empresa Wondershare, e o Audacity, editor de áudio, software livre sob licença da GNU General Public License. Todos esses estavam à disposição do pesquisador no computador institucional cedido pelo Centro Cultural da UFTM, setor em que o pesquisador é servidor efetivo.

O processo de captação de imagem para orientação dos processos no computador foi completo com a gravação de captura de tela para as orientações práticas realizadas no software Microsoft Word e na plataforma Google Drive da Google, empregando-se o software de gravação e streaming gratuito, OBS, que possuí código aberto mantido pela OBS Project. A aplicação conta com o recurso de captura de imagem. Para a captação dos áudios das narrações foi utilizado o aplicativo de smartphone para sistema operacional Android, 'Gravador de Voz' da empresa BACHA Soft, o aplicativo é gratuito e está disponível na loja virtual da Google, Play Store.

Após a decupagem - listagem do material filmado, ou gravado em dispositivo áudio, para posterior seleção dos trechos a serem aproveitados na edição - das gravações, foi iniciado o processo de edição. O processo de edição começou com o tratamento dos áudios utilizando a aplicação Audacity, pelo qual foi aplicado o efeito de equalização, assim como foram cortadas as partes que continham erros e silenciados os intervalos entre falas para remoção completa de sons. O processo 
de equalização é aplicado para melhorar o equilíbrio entre os graves e agudos (curva de resposta de frequência) tornando o mais adequado propósito do vídeo, assim como a remoção de ruídos, onde a aplicação remove os sons definidos como indesejáveis na gravação (BAUER, 2018).

Após o tratamento dos áudios, partiu-se para a montagem do vídeo, em que foi realizado o ordenamento dos cortes de cenas e de áudios, que após estruturado dividiu-se em três vídeos.

Com os vídeos finalizados, foi realizado o processo de exportação que transforma o projeto de edição em vídeo. Após os vídeos serem exportados, foi realizado o processo de revisão, em que são assistidos os vídeos, por uma ou mais vezes, a procura de pontos incorretos ou que possam ser melhorados. Após identificados os pontos a serem corrigidos, as edições foram realizadas e os vídeos finais foram exportados novamente.

O processo de avaliação teve início com o envio dos vídeos aos participantes da pesquisa, para que esses, avaliassem o vídeo quanto à sua adequação de conteúdo, por meio de questionário on-line. O envio aconteceu por e-mail e a avaliação aconteceu dos dias onze a quinze de janeiro de 2021.

A avaliação explorou três critérios: a) eficácia; b) adequação da forma (clareza, tamanho, linguagem); e c) adequação de conteúdo (coesão, coerência e concisão), o instrumento foi constituído por questões de escalas e questões abertas para justificativa das respostas.

No critério eficácia, foi inquerido aos participantes se "O vídeo orienta satisfatoriamente todos os procedimentos da elaboração de um questionário on-line para pesquisa com seres humanos", em que foi utilizada uma escala com 5 opções, variando de 1 (discordo completamente) até 5 (concordo completamente), junto ao questionamento, foi disposta uma questão aberta com "Justifique sua resposta".

No critério de adequação da forma, foram questionados ao participante se "A qualidade audiovisual é adequada"; "A linguagem utilizada é adequada"; "O tamanho é adequado"; e "O formato é adequado". Os questionamentos para esse critério, como no critério anterior, foram realizados com escalas, variando de 1 (discordo completamente) até 5 (concordo completamente), que foram acompanhadas por uma pergunta aberta para justificativa da resposta, "Justifique sua resposta".

A avaliação do critério adequação de conteúdo foi realizada quanto a coerência, em referência a normatização da ética em pesquisa, com o questionamento "A mensagem do vídeo é coerente com o que determina a normatização ética"; quanto a coesão, com os questionamentos "Há relação lógica entre os elementos expostos no vídeo" e "Há harmonia e conexão entre os elementos da mensagem"; e quanto a concisão (precisão, objetividade), com o questionamento "O vídeo é objetivo". Todos 
esses questionamentos, igualmente, foram realizados por escalas, variando de 1 (discordo completamente) até 5 (concordo completamente).

A avaliação foi aplicada com uso do serviço Google Forms, que realiza a tabulação dos dados em tabelas. O questionário não possui espaço para identificação do respondente, com fins a preservar a identidade e evitar que os participantes se sintam constrangidos a serem honestos sobre o vídeo produzido. A avaliação foi submetida a todos os membros do comitê que atendiam aos critérios de inclusão do estudo, independentemente se haviam participado do seminário.

Os dados coletados nas questões de escala foram organizados e dispostos com emprego de estatística descritiva, em que foi apresentado a média, porém, por se tratar de uma amostra pequena e sem significância estatística, esses dados serviram apenas para mostrar se o vídeo foi satisfatoriamente avaliado para subsidiar na decisão de utilizá-lo ou não.

O material produzido resultou em três vídeos, o primeiro apresenta uma introdução da proposta dos três vídeos e contextualiza historicamente a ética em pesquisa e o sistema CEP-CONEP. Esse vídeo possuí quatro minutos e vinte e quatro segundos.

O segundo apresenta os processos de consentimento e assentimento e ensina como estruturar um Termo de Consentimento Livre e Esclarecido. Ele conta com dez minutos e dezoito segundo de extensão.

O terceiro vídeo orienta como construir um questionário on-line com o termo de consentimento utilizando a ferramenta Google Forms, possui nove minutos e trinta e dois segundos. Os três vídeos juntos contabilizam vinte e quatro minutos e quatorze segundos.

A pesquisa contou com a participação de seis participantes na fase de planejamento (elaboração, edição e aprovação do roteiro) que aconteceu por seminário; e seis participantes na fase de avaliação (resposta a um questionário com nove questões em escala e quatro questões abertas). A avaliação ocorreu com questionário on-line e os resultados foram analisados de forma quantitativa.

O resultado final da avaliação foi positivo, a avaliação foi feita considerando os critérios: atingimento do objetivo proposto, adequação da forma e adequação do conteúdo.

O primeiro critério aferido apresentou uma média de concordância de 93,3\% atingindo 28 pontos em 30 possíveis, sendo que quatro participantes concordaram plenamente que os vídeos atingiram o objetivo proposto. O objetivo proposto em avaliação era orientar um pesquisador como realizar um questionário on-line em concordância com a ética em pesquisa.

$\mathrm{O}$ segundo critério avaliado se referia à adequação da forma. $\mathrm{O}$ critério foi avaliado em quatro questionamentos de adequação: qualidade audiovisual, linguagem utilizada, tamanho e formato. $\mathrm{O}$ primeiro questionamento deste critério "qualidade audiovisual" apresentou média de concordância de $90 \%$ atingindo 27 pontos em 30 possíveis. O segundo questionamento deste critério "linguagem 
utilizada" apresentou média de concordância de 100\%, atingindo 30 pontos em 30 possíveis. O terceiro questionamento deste critério "tamanho" apresentou média de concordância de 96,6\% atingindo 29 pontos em 30 possíveis. O quarto questionamento do critério de adequação de forma, inqueriu a respeito do "formato" dos vídeos, o resultado desse questionamento mostrou média de 96,6\% de adequação quanto ao formato, sendo que foram atingidos 28 pontos em 30 possíveis.

O último critério avaliado foi referente à adequação de conteúdo. A aferição do critério ocorreu com quatro questionamentos: coerência com a normatização ética; relação lógica dos elementos expostos; harmonia e conexão dos elementos; e objetividade. O primeiro questionamento deste critério "coerência com normatização ética" demonstrou média de concordância de $96,6 \%$ alcançando 29 pontos em 30 possíveis. O segundo questionamento "lógica entre os elementos expostos no vídeo" apresentou média de concordância de 96,6\%, com pontuação de 29 pontos em 30 possíveis. O terceiro questionamento do critério adequação de conteúdo "harmonia e conexão entre os elementos do vídeo" mostrou média de concordância de 96,6\% com 29 pontos em 30 possíveis. O quarto e último questionamento realizado foi "objetividade do vídeo" e apresentou, igualmente, $96,6 \%$ de média de concordância, com 29 pontos em 30 possíveis.

Cabe ressaltar que os questionamentos de adequação objetivaram mensurar a possibilidade de uso do material e não somente a qualidade final alcançada, ou seja, os participantes do estudo analisaram os critérios tendo como referência a possibilidade de uso do vídeo no futuro e não somente o nível de qualidade. Com isso, os resultados obtidos na avaliação dos critérios supracitados mostram que, na média geral dos critérios avaliados, há adequação para uso dos vídeos, a partir dos critérios avaliados, de 95,18\%, sendo que a avaliação global mostrou o alcance de 257 pontos em 270 possíveis.

Esses resultados apontam que, segundo os membros do Comitê de Ética em Pesquisa a que o vídeo foi proposto, há um satisfatório grau de adequação, indicando possibilidade de o conteúdo ser disponibilizado em momento futuro.

Contudo, essa avaliação de adequação mostra fragilidades quanto ao alcance de sua confiança para interpretações que ultrapassam a aplicação do produto final conseguido. O questionário aplicado não possui fundamentação teórica quanto a validação de conteúdo, pois a finalidade dessas aferições era de avaliação do processo de investigação-ação advinda da metodologia de pesquisaação aplicada. Ressalta-se ainda não há confiabilidade estatística, pois a seleção da amostra foi intencional e conta com um universo limitado de indivíduos, característico da proposta metodológica em uso. 
A captação apresentou desafios que não foram superados durante a fase de edição, como qualidade da captação do áudio e a iluminação do local de captação. A última influenciando diretamente no procedimento de digitalização do cenário pela técnica de Chroma Keying.

Quanto ao conteúdo, apesar da realização do seminário para a edição do roteiro, há informações que tiveram sua ausência notada apenas após o processo finalizado, o que aponta a necessidade de mais de um seminário no processo de pesquisa-ação para a construção dos vídeos.

No processo de apresentação, notou-se que a uniformidade no ritmo da fala e o padrão de expressões físicas e de postura só são adquiridas quando há um processo de acompanhamento realizado durante o processo de filmagem, in loco, pois, uma vez gravado, o material jamais contará com excelência na uniformidade audiovisual se necessitar de adição de novas cenas. A uniformidade é diretamente prejudicada nos casos em que há necessidade de substituição de trechos que são gravados em ocasiões diferentes, certo que sempre ocorrerão mudanças na luz, no áudio e na atitude do apresentador.

O processo de edição originalmente previsto no projeto de pesquisa não pode ser cumprido conforme planejado. Foram enfrentadas limitações extraordinárias quanto a aplicações que seriam empregadas no processo de tratamento do vídeo, as aplicações originalmente previstas não estavam disponíveis à época da edição por motivos de ordem maior.

\section{CONCLUSÃO}

O processo de investigação-ação proposto pelo método de pesquisa-ação mostrou-se uma importante ferramenta para pesquisas que visam o melhoramento de processos em um circunscrito campo de atuação que envolva indivíduos compartilhando um objetivo comum. A pesquisa-ação como método possui limitações quanto a apresentação de resultados definitivos por carecer de linearidade e limites a sua execução, visto que o processo se estende enquanto houver melhoramentos a serem feitos.

No viés acadêmico, Tripp aponta a dificuldade encontrada ao se realizar dissertações a partir desse tipo de processo "[...] porque não é possível especificar com antecedência qual conhecimento será obtido nem quais resultados práticos serão alcançados.” (TRIPP, 2005, p. 259). Sendo assim o autor defende que é mais comum a realização de pesquisas de estudo de caso sobre processos de pesquisa-ação, o que pode se notar na configuração deste trabalho.

Como método, a ação de investigar e aplicar os resultados dessa investigação na prática de um grupo se mostrou de imenso valor para esse estudo, pois, além de se mostrar um processo democraticamente viável, produziu resultados que poderão de fato, auxiliar na prática ordinária das 
atividades do Comitê de Ética em Pesquisa, em conveniente e oportuno momento para a comunidade de pesquisadores em que se insere. Além de ter incentivado a iluminação de elementos da prática diária de um grupo que possuí em seus meandros questões obscuras sem consolidação normativa e que pelo caráter especifico, podem vir a não ter.

Quanto ao seu valor científico, a academia e a ciência se solidifica sobre dados que no decorrer do tempo são observados, controlados, colocados a prova e refutados, e o método pode se mostrar útil como processo, mas pode se mostrar pouco incisivo se considerado sozinho.

Evidenciou-se no decorrer deste estudo, que o processo de validação de conteúdo com juízes peritos e a aferição junto ao público alvo do produto desenvolvido, pode ser uma saída para maximizar a confiabilidade dos resultados. Por isso, considera-se que esse processo não deve ser finalizado neste trabalho acadêmico, mas se tornar uma base para novos estudos a respeito do tema no futuro, com vistas a ampliar, aprofundar e consolidar o material produzido.

Acima de tudo, conclui-se que esse trabalho é um esforço de aprimoramento entre a relação estado e sociedade, onde um serviço público está a ser aprimorado em proveito do usuário. Com isso, percebe-se que o fomento a cultura de criação de novos canais de comunicação com uso das tecnologias da informação apresenta-se como uma viável saída para a democratização da informação entre a gestão estatal e a sociedade. Esses canais indicam ser um caminho para o florescimento da transparência da ação governamental em busca de ideais democráticos e equitativos, em favorecimento da ação coordenada entre sociedade e estado (RIBEIRO; SOPHIA; GRIGORIO, 2007).

No contexto da ética em pesquisa, e seu gestor nacional, o sistema CEP-CONEP, a inovação tecnológica tem apresentado avanços grandiosos nos últimos sete anos, seja com o sistema virtual da Plataforma Brasil, ou pelos recursos tecnológicos empregados na manutenção do constante aprimoramento do sistema com suas capacitações e acompanhamentos, desenvolvidas em um território de extensões continentais como o do Brasil.

O caráter educativo advindo da disposição normativa e conceitual do sistema, beneficia-se com a adoção de soluções tecnológicas para problemas antigos e novos, previsíveis e imprevisíveis, e que não dão sinais de cessão. Com isso, cabe aos indivíduos imbuídos da responsabilidade de guardar a ética em pesquisa, debruçarem-se sobre novas possibilidades e abraçarem o ideal de busca constante pelo aprimoramento dos meios de comunicação e práticas educativas junto aos seus públicos, sejam esses participantes de pesquisas, pesquisadores ou instituições proponentes de estudos.

Finalmente, entende-se que esse processo de inovação poderá servir como um mapa para novas propostas no que diz respeito a educação da ética em pesquisa na universidade e fora dela, 
fortalecendo os laços entre a ciência e a sociedade, em respeito ao bem individual e coletivo, na busca constante pelo progresso humano.

\section{REFERÊNCIAS}

AQUINO, E. M. L. et al. Medidas de distanciamento social no controle da pandemia de COVID19: potenciais impactos e desafios no Brasil. Rev. Ciênc. Saúde Coletiva, Rio de Janeiro, v. 25, supl. 1, p. 2423-2446, jun., 2020. Disponível em: http://dx.doi.org/10.1590/141381232020256.1 .10502020 .

ASSOCIAÇÃO MÉDICA MUNDIAL. Declaração de Helsinque da Associação Médica Mundial (WMA): princípios éticos para pesquisa médica envolvendo seres humanos. 06/1964. Acessível em http://www.amb.org.br/_arquivos/_downloads/491535001395167888_

DoHBrazilianPortugueseVersionRev.pdf

BARDIN, L. Análise de conteúdo. 1. ed. Lisboa: Edições 70, 1977.

BASTOS, W. G.; REZENDE FILHO, L. A. C. de; PASTOR JUNIOR, A. de A. Produção de vídeo educativo por licenciandos: um estudo sobre recepção fílmica e modos de leitura. Rev. Ens. Pesqui. Educ. Ciênc. (Belo Horizonte), Belo Horizonte, v. 17, n. 1, p. 39-58, abr., 2015. Disponível em: https://doi.org/10.1590/1983-211720175170102.

BAUER, M. Sistema para equalização paramétrica de áudio em tempo real. 2018. $54 \mathrm{f}$. Trabalho de Conclusão de Curso (Graduação) - Universidade Tecnológica Federal do Paraná, Pato Branco, 2018. Disponível em: http://repositorio.roca.utfpr.edu.br/jspui/handle/1/12120

BEZERRA, A. C. V. et al. Fatores associados ao comportamento da população durante o isolamento social na pandemia de COVID-19. Rev. Ciênc. saúde coletiva, Rio de Janeiro, v. 25, supl. 1, p. 2411-2421, jun., 2020.

Disponível em: https://doi.org/10.1590/1413-81232020256.1.10792020.

BRASIL. Ministério da Saúde. Conselho Nacional de Saúde. Resolução no 466, de 12 de dezembro de 2012. Diário Oficial [da] República Federativa do Brasil. Brasília, DF, 12 dez. 2012. Disponível em:

<http://bvsms.saude.gov.br/bvs/saudelegis/cns/2013/res0466_12_12_2012.html>.

BRASIL. Ministério da Saúde. Conselho Nacional de Saúde. Norma Operacional nº 001/2013. Brasília, 2013. p. 1-14. Disponível em:

http://conselho.saude.gov.br/web_comissoes/conep/aquivos/CNS\%20\%20Norma\%20Operacion al\%20001\%20-\%20conep\%20finalizada\%2030-09.pdf $>$.

BRASIL. Ministério da Saúde. Conselho Nacional de Saúde. Resolução no ${ }^{\text {510 }}$, de 7 de abril de 2016. Diário Oficial [da] República Federativa do Brasil, Brasília, DF, 24 maio 2016. Seção 1. p. 44-46. Disponível em: 〈http://conselho. saude.gov.br/resolucoes/2016/Reso510.pdf>. 
CAICEDO-OCHOA, Y.; REBELLÓN-SÁNCHEZ, D.; PEÑALOZA-RALLÓN, M.; CORTÉSMOTTA, H.; MÉNDEZ-FANDIÑO, Y. Effective Reproductive Number estimation for initial stage of COVID-19 pandemic in Latin American Countries. International Journal of Infectious Diseases, vol. 95, p. 316-318, 2020. Disponível em: https://doi.org/10.1016/j.ijid.2020.04.069.

CAMPOS, CESAR FERRAZ; DE PAULA, LUCIANO BERNARDES. O uso da internet na educação e o panorama brasileiro atual. Revista Científica e-Locução, v. 1, n. 17, p. 21-21, 2020.

COMPARATO, D. Da criação ao roteiro: teoria e prática. São Paulo: Editora Summus, 2009.

ESCOSTEGUY, A. C. Circuitos de cultura/circuitos de comunicação: um protocolo analítico de integração da produção e da recepção. Revista Comunicação, Mídia e Consumo, São Paulo, SP, v. 4, n.11, p. 115 - 135, nov., 2007. Disponível em:

http://revistacmc.espm.br/index.php/revistacmc/article/view/111.

EVANS, J.; MATHUR, A. The value of online survey. Internet Research, v. 15, n. 2, p. 195-219, 2005. Disponível em:

<https://www.researchgate.net/profile/Joel_Evans4/publication/220146842_The_Value_of_Online _Surveys/links/5519365c0cf273292e70e1c5.pdf>

FALEIROS, F. et al. USE OF VIRTUAL QUESTIONNAIRE AND DISSEMINATION AS A DATA COLLECTION STRATEGY IN SCIENTIFIC STUDIES. Rev. Texto Contexto

Enfermagem, Florianópolis, SC. v. 25, n. 4, 2016. Disponível em: Disponível em: https://doi.org/10.1590/0104-07072016003880014.

FREITAS, H.; JANISSEK-MUNIZ, R.; MOSCAROLA, J. Uso da Internet no processo de pesquisa e análise de dados. Associação Nacional de Empresas de Pesquisa. Anais. São Paulo, 2004. Disponível em: https://lume.ufrgs.br/handle/10183/4801

FREITAS, C. B. D. Os comitês de ética em pesquisa: evolução e regulamentação. Rev. Bioética, v.6, n. 2., p. 189-95, 1998. Disponível em:

https://revistabioetica.cfm.org.br/index.php/revista_bioetica/article/view/347/414

GIL, A. C. Métodos e técnicas de pesquisa social. 6.ed. São Paulo: Atlas, 2008.

GORBALENYA, A. E. et al. Severe acute respiratory syndrome-related coronavirus: The species and its viruses - a statement of the Coronavirus Study Group. Coronaviridae Study Group of the International Committee on Taxonomy of Viruses. fev. 2020. Disponível em:

<http://hdl.handle.net/10261/212994

GUERRIERO, I. C. Z. A resolução 510/16: diretrizes éticas para pesquisas em Ciências Humanas e Sociais. Cad. Ter. Ocup., UFSCar, São Carlos, SP, v. 24, n. 3, p. 429-433, 2016 http://dx.doi.org/10.4322/0104-4931.ctoED2403.

GUERRIERO, I. C. Z. Resolução n ${ }^{\circ}$ 510, de 7 de abril de 2016 que trata das especificidades éticas das pesquisas nas ciências humanas e sociais e de outras que utilizam metodologias próprias dessas áreas. Ciência \& Saúde Coletiva, Rio de Janeiro, v. 21, n. 8, p. 2619-2630, 2016. 
NOVOA, P. C. R. O que muda na ética em pesquisa no Brasil: resolução 466/12 do Conselho Nacional de Saúde. Rev. Einstein (São Paulo), São Paulo, SP. v. 12, n. 1, p. viivix, mar., 2014. Disponível http://dx.doi.org/10.1590/S1679-45082014ED3077.

OLIVEIRA, N. A. S. de. História e internet: conexões possíveis. Revista Tempo e Argumento, Florianópolis, SC. v. 6, n.12, p. 23 - 53, mai./ago., 2014. Acessado em 14 de outubro de 2020. Disponível em: https://doi.org/10.5965/2175180306122014023. ORGANIZAÇÃO PANAMERICANA DE SAÚDE (OPAS). Folha informativa - COVID-19 (doença causada pelo novo coronavírus). Consultado em 1 de outubro de 2020. Disponível em: https://www.paho.org/pt/covid19

PASINI, C. G. D.; CARVALHO, É. de; ALMEIDA, L. H. C. A educação híbrida em tempos de pandemia: algumas considerações. Observatório Socie-economico da COVID-19. Universidade Federal de Santa Maria, RS. 2020. Disponível em: https://www.ufsm.br/app/uploads/sites/820/2020/06/Textos-para-Discussao-09-Educacao-Hibridaem-Tempos-de-Pandemia.pdf

PASTOR JUNIOR, A. de A.; REZENDE, L. A. de C.; BASTOS, W. G. Recepção audiovisual na educação médica: leituras de um vídeo educativo de psicologia médica por estudantes de medicina. Rev. bras. educ. med., Rio de Janeiro, RJ. v. 36, n. 4, p. 516-523, dez., 2012. Disponível em: https://doi.org/10.1590/S0100-55022012000600010

RIBEIRO, P.; SOPHIA, D. C.; GRIGORIO, D. de A. Gestão governamental e sociedade: informação, tecnologia e produção científica. Rev. Ciênc. saúde coletiva, Rio de Janeiro, v. 12, n. 3, p. 623-631, jun., 2007. Disponível em: http://dx.doi.org/10.1590/S1413-81232007000300012.

SAMPAIO, R. M. Práticas de ensino e letramentos em tempos de pandemia da COVID-19. Resourch, Society and Development, v.9, n.7, 2020. Disponível em: http://dx.doi.org/10.33448/rsd-v9i7.4430.

SCHWARTZ, F. P. Distanciamento social e o achatamento das curvas de mortalidade por COVID-19: uma comparação entre o Brasil e epicentros da pandemia. Revista Thema, v. 18 (ESPECIAL), p. 54-69, 2020. Disponível em:

https://doi.org/10.15536/thema.V18.Especial.2020.54-69.1810

SILBIGER, L. N. O potencial educativo do audiovisual na educação formal. In: FIDALGO, A; SERRA, P. (Org.). Campos da comunicação: livro Actas do III SOPCOM, VI LUSOCOM e II IBÉRICO. Convilhã: Universidade da Beira Interior, 2005. p. 375-381.Disponível em: http://labcom.ubi.pt/ficheiros/ACTAS\%20VOL\%204.pdf

SILVA, S. M. da; SANTOS, C. C. M.; SIQUEIRA, J. de O. O uso do questionário eletrônico na pesquisa acadêmica: um caso de uso na Escola Politécnica da Universidade de São Paulo (1998). Anais... South Padre Island: BALAS/University of Texas, 1998.

SOUSA, A. F. L. et al. Sexo casual entre HSH durante o período de abrigamento para evitar a propagação da covid-19: resultados de pesquisas nacionais online no Brasil e em Portugal. MedRxiv, jun., 2020. Disponível em: https://www.medrxiv.org/content/10.1101/2020.06.07.20113142v2

TEIXEIRA, R. K. C.; YAMAKI, V. N.; GONÇALVES, T. B. BOTELHO, N. M. Comitê de 
Ética em Pesquisa: história e atualidade. Biblioteca Regional da Saúde. Organização PanAmericana da Saúde. 2012. Disponível em: http://files.bvs.br/upload/S/01015907/2012/v26n4/a3494.pdf

THIOLLENT, M. Metodologia da pesquisa - ação. 2. ed. São Paulo: Cortez, 1986.

TORRINI, D. Questionários on-line. Métodos de Pesquisa em Ciências Sociais - Bloco quantitativo. São Paulo, SP: CEBRAP/SESC, 2016. P. 55-75. Disponível em: http://bibliotecavirtual.cebrap.org.br/arquivos/2017_E-BOOK\%20SescCebrap_\%20Metodos\%20e\%20tecnicas\%20em\%20CS\%20-\%20Bloco\%20Quantitativo.pdf

TRIPP, D. Pesquisa-ação: uma introdução metodológica. Ver. Educ. Pesqui., São Paulo, SP. V. 31, n. 3, p. 443-466, 2005. Disponível em: https://doi.org/10.1590/S1517-97022005000300009.

VASCONCELLOS-GUEDES, L.; GUEDES, L. F. Ascenção. E-surveys: Vantagens e Limitações dos Questionários Eletrônicos via Internet no Contexto da Pesquisa Científica. In: SEMEAD SEMINÁRIO EM ADMINISTRAÇÃO FEA/USP, 10., São Paulo, SP. Anais... 2007. Disponível em: http://sistema.semead.com.br/10semead/sistema/resultado/trabalhosPDF/420.pdf

VAN DEN BERGH, F. LALIOTI, V. Software chroma keying in an immersive virtual environment. South African Computer Journal, nº. 24, 1999. Disponível em:

http://hdl.handle.net/10500/24376

VIKRAM, S. Web 2.0 with Past and Future. International Journal of Systems, Algorithms \& Applications. p. 190-193, 2013. Disponível em:

https://www.academia.edu/14197952/Web_2_0_with_Past_and_Future

WORLD HEALTH ORGANIZATION (WHO). Pneumonia of unknown cause - China. Geneva. WHO. 2020. Disponível em: https://www.who.int/csr/don/05-january-2020-pneumonia-ofunkown-cause-china/en/

WORLD HEALTH ORGANIZATION (WHO). WHO Director-General's statement on IHR Emergency Committee on Novel Coronavirus (2019-nCoV). Geneva. WHO. 2020. Disponível em: https://www.who.int/news-room/detail/23-01-2020-statement-on-the-meeting-of-theinternational-health-regulations-(2005)-emergency-committee-regarding-the-outbreak-of-novelcoronavirus-(2019-ncov). 